\title{
STASIUN SINGGAH SEMANAN INDAH SEBAGAI FASILITAS PENINGKATAN WELLNESS
}

\author{
Greselda Ruby ${ }^{1)}$, Andi Surya Kurnia ${ }^{21}$ \\ 1)Program Studi S1 Arsitektur, Fakultas Teknik, Universitas Tarumanagara, greseldaruby.gr@gmail.com \\ 2)Program Studi S1 Arsitektur, Fakultas Teknik, Universitas Tarumanagara, andik@ft.untar.ac.id
}

\begin{abstract}
Abstrak
Mobilitas komuter menjadi salah satu faktor yang menyebabkan kepadatan penduduk Jakarta semakin meningkat. Sebagian besar penduduk dan komuter Jakarta menghabiskan waktu dengan aktivitas rutin seperti bekerja dan belajar sehingga tidak mempunyai waktu luang untuk mewujudkan gaya hidup sehat seperti berolahraga dan berelaksasi. Proyek third place ini menjadi fasilitas peningkatan hidup sehat sekaligus tempat singgah karena didukung dengan lokasi yang berhubungan langsung dengan pusat mobilitas dan aktivitas masyarakat Jakarta yaitu stasiun kereta komuter Rawa Buaya yang terhubung langsung dengan aktivitas perkantoran. Fasilitas tersebut menyangkut kegiatan pemenuhan kebutuhan fisiologis manusia (Abraham Maslow (1908-1970) dalam Asmadi (2008:18)) yang meliputi kegiatan istirahat, makan, olahraga, dan relaksasi. Dengan demikian, program yang diangkat berupa peningkatan physical wellness seperti kapsul tidur indoor dan outdoor, serta food court; mental wellness seperti kelas yoga, meditasi, zumba, spa, dan sauna; serta social wellness seperti game station, outdoor waiting area, dan charging station. Perancangan proyek thrid place ini menggunakan pendekatan responses to site dengan mempertimbangkan orientasi terhadap lokasi tapak di sudut jalan, akses pedestrian, dan neighborhood atau bangunan sekitar. Metode tersebut digunakan dalam membentuk massa bangunan yang menyesuaikan orientasi dan memperhatikan cahaya alami, menentukan akses utama pedestrian di dalam tapak, meletakkan program-program sesuai dengan fungsi sekitar, dan membuat program di lantai dasar sebagai program bersama.
\end{abstract}

Kata kunci: mobilitas; tanggap tapak; wellness

\begin{abstract}
Mobility of commuters is one of the factors that causing Jakarta's population density increases. Most of Jakarta residents and commuters spend time with routine activities such as work and study so they do not have free time to create a healthy lifestyle such as exercise and relaxation. This third place project is a facility to improve healthy life and as a layover place because it is supported by its location that is directly related to Jakarta mobility and activities center, named Rawa Buaya commuter train station which is directly connected with office activities. The facilities involve activities to fulfill human physiological needs (Abraham Maslow (1908-1970) in Asmadi (2008:18)) which includes rest, eating, exercise, and relaxation. Thus, the programs that use in the project is to increase physical wellness such as indoor and outdoor sleeping capsules, and food court; mental wellness such as yoga, meditation, zumba, spa, and sauna classes; and social wellness such as game stations, outdoor waiting areas, and charging stations. The design of the thrid place project uses the responses to site approach by considering the orientation to the location of the site at the corner of the road, pedestrian access, and the neighborhood or surrounding buildings. The method is used in forming building masses that pay attention to orientation and natural light, determine the main pedestrian access in the site, place programs near the surrounding functions, and make programs on the ground floor for the public.
\end{abstract}

Keywords: mobility; respond to site; wellness 


\section{PENDAHULUAN}

\section{Latar Belakang}

Badan Pusat Statistik (2019) menyatakan bahwa kepadatan penduduk di Jakarta telah mencapai 15.938 jiwa per kilometer persegi (jiwa $/ \mathrm{km}^{2}$ ). Kepadatan ini ditambah dengan adanya mobilitas penduduk, baik yang bersifat permanen maupun non-permanen. Hal ini dibuktikan dengan hasil Survei Komuter Jabodetabek pada tahun 2019 yang menyatakan bahwa 1,2 juta penduduk luar Jakarta melakukan aktivitas di Jakarta setiap harinya. Aktivitas dan mobilitas yang rutin dilakukan oleh sebagian besar penduduk di Jakarta menghilangkan kesempatan untuk menerapkan gaya hidup sehat. Hal ini dibuktikan oleh Badan Pusat Statistik (2016) yang menyatakan 72,39\% penduduk Jakarta tidak rutin berolahraga. Millenials At Work Survey Asia Pacific (2016) juga menyatakan bahwa 56\% perkerja muda tidak mempunyai waktu berolahraga serta Jakarta Health Week menyatakan bahwa $60 \%$ pekerja menghabiskan waktu lebih dari satu jam untuk melakukan perjalanan atau bermobilitas.

Fasilitas peningkatan hidup sehat atau wellness menjadi solusi di tengah aktivitas dan mobilitas baik penduduk maupun komuter di Jakarta. Hal ini didukung dengan pemilihan lokasi perancangan yang berada di tengah antara first dan second place sehingga dapat menjadi tempat singgah atau pemberhentian bagi penduduk yang melakukan mobilitas non-permanen di Jakarta. Tempat singgah yang dimaksud berkaitan dengan fasilitas peningkatan physical wellness seperti kapsul tidur indoor dan outdoor, serta food court; mental wellness seperti kelas yoga, meditasi, zumba, spa, dan sauna; serta social wellness seperti game station, outdoor waiting area, dan charging station. Fasilitas tersebut menjadi sebuah third place yang dapat digunakan baik oleh masyarakat maupun komuter di sekitar Duri Kosambi khususnya Perumahan Taman Semanan Indah dan Stasiun Rawa Buaya. Hal demikian disebabkan oleh pemenuhan beberapa kriteria third place di dalam fasilitas wellness tersebut, di antaranya yaitu netral, leveler, regulars, accessible, conversation, dan playful.

\section{Rumusan Permasalahan}

Aktivitas dan mobilitas masyarakat di sekitar lokasi tapak relatif tinggi karena dipengaruhi dengan keberadaaan stasiun kereta komuter Rawa Buaya yang merupakan gerbang kedatangan komuter di Semanan Indah. Aktivitas perkantoran mendominasi di kawasan ini sehingga membentuk gaya hidup masyarakat kota dengan tingkat kesibukan yang tinggi. Hal ini menghilangkan kesempatan mereka untuk mewujudkan gaya hidup sehat seperti berolahraga, berelaksasi, dan pemenuhan kebutuhan nutrisi. Hilangnya kesempatan untuk mewujudkan gaya hidup sehat, menjadikan proyek third place dengan fasilitas peningkatan hidup sehat baik secara fisik, mental, maupun sosial sangat dibutuhkan oleh masyarakat maupun komuter di tengah menjalankan aktivitas dengan tingkat kesibukan yang tinggi. Dengan demikian, proyek Stasiun Singgah Semanan Indah tidak hanya mencakup fasilitas peningkatan hidup sehat melainkan juga menjadi fasilitas singgah.

\section{Tujuan}

Proyek ini dibuat dengan tujuan untuk membentuk third place di tengah first dan second place dengan menerapkan metode responses to site dalam menentukan bentuk, orientasi, dan layout massa; menentukan akses utama pedestrian; serta menentukan jenis dan layout program di dalam tapak yang sesuai dengan fungsi sekitar. Program yang dimaksud berupa program singgah seperti kapsul tidur, yoga, meditasi, zumba, spa, dan sauna. Proyek third place ini menjadi gagasan bagi pihak terkait dalam membangun fasilitas kota agar tepat sasaran dan menjawab permasalahan serta kebutuhan masyarakat kota secara menyeluruh. Selain itu, proyek ini juga bermanfaat bagi masyarakat kota Jakarta maupun komuter agar dapat memenuhi kebutuhan fisiologisnya yang terdiri dari istirahat atau tidur, makan dan meningkatkan kebugaran fisik maupun mental di tengah aktivitas dan mobilitas. 


\section{KAJIAN LITERATUR}

Third place menurut Ray Oldenburg (1997:22) merupakan ruang antara, bukan tempat tinggal (home) maupun tempat kerja, yang membantu masyarakat kota agar bersifat humanis, terbuka, dinamis, dan produktif. Third place sebagai "ruang keluarga" dalam masyarakat merupakan tempat terjadinya pertukaran infromasi, interaksi, dan pembentukan komunitas masyarakat. Kriteria third place terdiri dari on neutral ground, tempat yang netral tanpa ikatan hukum, finansial, dan bebas untuk datang dan pergi; leveler, tempat bagi semua golongan tanpa melihat hirarki dan status sosialnya dalam masyarakat serta memiliki kedudukan yang sejajar; conversation sebagai aktivitas utama; accessible, tempat yang mudah diakses secara finansial dan menjadi pemenuhan kebutuhan pengunjungnya; regulars, mampu mengundang banyak orang untuk datang; plain \& unpretentious, mengundang masyarakat untuk datang tanpa keraguan dan terbuka bagi siapa saja; playful, tempat yang menyenangkan bagi masyarakat.

Third place sebagai ruang antara, menampung program yang dibutuhkan masyarakat sekitar. Program peningkatan wellness menjadi fokus dalam proyek Stasiun Singgah Semanan Indah ini. Wellness merupakan salah satu kebutuhan yang harus dipenuhi oleh manusia. Menurut Abraham Maslow (1908-1970) dalam Asmadi (2008:18), kebutuhan manusia dapat digolongkan menjadi lima tingkat kebutuhan, yaitu kebutuhan fisiologis, kebutuhan akan keselamatan dan keamanan, kebutuhan akan cinta dan dicintai, kebutuhan akan harga diri, dan aktualisasi diri. Semakin tinggi hierarki kebutuhan yang terpenuhi, semakin mudah seseorang mencapai derajat kemandirian dan kesejahteraan yang optimal. Untuk dapat mencapai aktualisasi diri, manusia harus bisa memenuhi kebutuhan paling dasar yaitu kebutuhan fisiologis yang merupakan kebutuhan primer dan menjadi syarat dasar bagi kelangsungan hidup manusia. Kebutuhan fisiologis ini mutlak terpenuhi diantaranya meliputi oksigen, air, makanan, istirahat dan tidur, penangan nyeri, pengaturan suhu tubuh, dan lainlain. Dengan memenuhi kebutuhan fisiologis, manusia dapat mencapai wellness atau kebugaran tubuh serta kesehatan fisik.

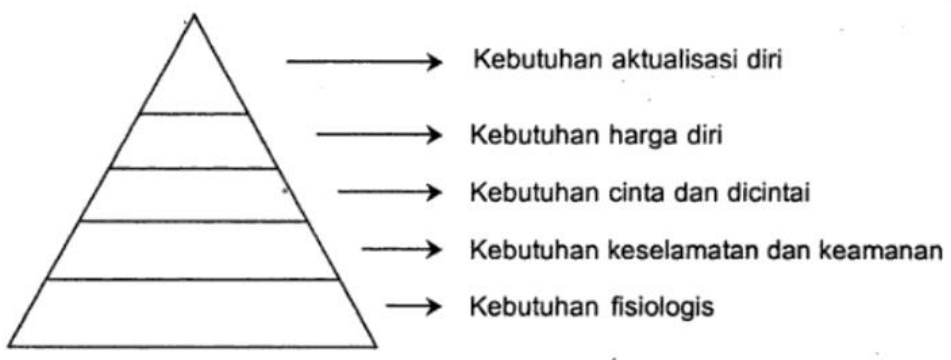

Gambar 1. Diagram Hierarki Kebutuhan Dasar Maslow Sumber: Asmadi, 2008

Sweeney (2000: 252) menyatakan bahwa wellness merupakan sebuah cara hidup yang berorientasi untuk mencapai kesehatan dan kesejahteraan secara optimal, dimana tubuh, pikiran, dan jiwa terintegrasi oleh individu untuk menjalani hidup secara penuh dalam komunitas manusia dan alam. Dengan demikian, setiap individu telah mencapai tahap kesehatan dan kesejahteraaan yang optimal. Wellness terbagi menjadi 7 bentuk, proyek ini hanya menerapkan 3 bentuk diantaranya yaitu:

a. Physical Wellness, meliputi kemampuan untuk mengerjakan tugas harian, meningkatkan kardiorespiratori, dan kecerdasan otot, mempertahankan kecukupan nutrisi dan lemak sehat dalam tubuh, dan mengurangi penyalahgunaan alkohol dan obat-obatan atau produk tembakau.

b. Spiritual Wellness. Spiritualitas adalah suatu kepercayaan terhadap nilai yang menjadi sumber informasi dalam kehidupan. The National Institute of Health memberikan saran 
untuk dapat mencapai spiritual wellness diantaranya yaitu melalui psikoterapi, support group, meditasi, yoga, dance therapy, music therapy, art therapy, doa dan mental healing, serta spa. Spa semula berorientasi pada suasana meditasi dan relaksasi dengan rendaman ramu-ramuan, pijatan, dan wangi-wangi yang dipersiapkan secara khusus untuk menjaga dan meningkatkan kebugaran dan kesehatan tubuh.

c. Sosial Wellness, merupakan kemampuan untuk mengembangkan dan memelihara hubungan dengan orang lain, menghargai dan memiliki sikap toleransi terhadap perbedaan pendapat dan kepercayaan.

Program utama yang diangkat dalam proyek ini berhubungan dengan aktivitas istirahat dalam konteks tempat singgah yang berupa kapsul tidur indoor dan outdoor dengan tingkat efisiensi yang tinggi. Hotel kapsul berkaitan dengan kegiatan tidur atau istirahat di dalam sebuah kapsul dengan kapasitas hanya untuk satu orang. Menurut Boye De Mente dalam Exotic Japan (1976), hotel kapsul memiliki dua tipe kamar diantaranya tipe kapsul yang berukuran kecil (mini) dengan ukuran $2 \times 1,5 \times 1 \mathrm{~m}^{3}$ yang berfungsi untuk tidur serta ukurannya hanya pas untuk satu orang (berasal dari Jepang); dan tipe kabin yang umunya hampir sama dengan kamar biasa, hanya pemasangan atau pekerjaan yang menerapkan sistem berbeda dari kamar pada umunya.

\section{METODE}

Metode yang digunakan dalam mendesain proyek ini yaitu "Responses to Site" atau tanggap terhadap tapak (Kari Jormakka, 2003:62). Perancangan proyek ini dimulai dari pemilihan kawasan dan mencari permasalahan, karakteristik, kebutuhan dan kekhasan dari kawasan tersebut, memilih lokasi tapak yang menjadi konsentrasi dari permasalahan tersebut, sampai akhirnya menghasilkan program yang tepat untuk kawasan terpilih.

Metode Responses to Site meliputi kontekstualisme dan kontras yang dituangkan ke dalam bentuk dan layout massa terhadap tapak, bentuk atap, fasad bangunan, serta zoning program yang dikaitkan dengan fungsi bangunan di sekitar tapak. Bentuk geometri segi empat diambil sebagai bentuk dasar massa bangunan sehingga menjadi kontekstual dengan bangunan sekitar. Bentuk atap dan fasad bangunan menerapkan bentuk diagonal sehingga menjadi kontras dengan bangunan sekitar yang didominasi dengan bentuk datar. Zoning dan layout program di dalam tapak memperhatikan hubungan fungsi bangunan sekitar sekitar, baik hunian maupun perkantoran.

\section{DISKUSI DAN HASIL}

\section{Lokasi}

Pemilihan lokasi tapak perancangan ini berdasarkan pada jarak pencapaian pejalan kaki terhadap titik transit Stasiun Rawa Buaya ( \pm 280 meter) dan tidak masuk ke dalam wilayah perumahan Taman Semanan Indah supaya tidak menimbulkan kesan eksklusif melainkan bersifat netral bagi semua orang untuk bisa datang tanpa melihat latar belakangnya. 


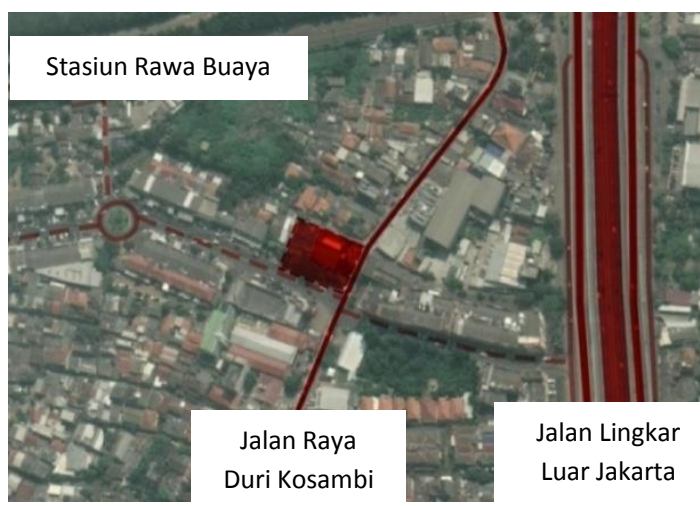

Gambar 2. Lokasi Tapak Perancangan Terpilih

Sumber: Penulis, 2020

Data adminintrasi tapak dijabarkan sebagai berikut Luas tapak $=2064 \mathrm{~m}^{2} ; \mathrm{KDB}=60 \%=1238,4$ $\mathrm{m}^{2} ; \mathrm{KLB}=2,4=4953,6 \mathrm{~m}^{2} ; \mathrm{KB}=4 ; \mathrm{KDH}=30 \%=619,2 \mathrm{~m}^{2} ; \mathrm{KTB}=55 \%=1135,2 \mathrm{~m}^{2}$; Sub Zona =K.1; Zona =Zona Perkantoran, Perdagangan, dan Jasa.

Lokasi tapak yang berada di persimpangan jalan dan dekat dengan stasiun Rawa Buaya menyebabkan tingginya mobilitas di sekitar tapak sehingga menjadi simpul strategis untuk suatu third place sebagai fasilitas singgah atau pemberhentian bagi komuter maupun masyarakat. Hal ini juga didukung dengan lokasi tapak yang menjadi perlintasan first dan second place sehingga tapak berperan sebagai pusat atau titik pertemuan baik kendaraan maupun pedestrian.

Pemilihan lokasi tapak perancangan ini didasari dengan mempertimbangkan parameter:

a. Kemudahan akses pedestrian menuju stasiun rawa buaya

Tapak sejajar dengan jalur pedestrian yang mengarah ke stasiun Rawa Buaya dan dilengkapi dengan kompleks pertokoan. Akses pedestrian menuju lokasi tapak relatif mudah dan dilengkapi dengan jalur pedestrian.

b. Kemudahan akses pedestrian menuju Perumahan Taman Semanan Indah

Tapak berada di dalam kompleks perumahan Taman Semanan Indah sehingga akses bagi masyarakat perumahan realtif mudah karena sudah dilengkapi dengan jalur pedestrian.

c. Kemudahan akses pedestrian dari kompleks perkantoran

Lokasi tapak bersilangan dengan kompleks perkantoran sehingga akses pedestrian relatif sulit. Dengan demikian, solusi untuk proyek ini yaitu menggunakan pelican crossing.

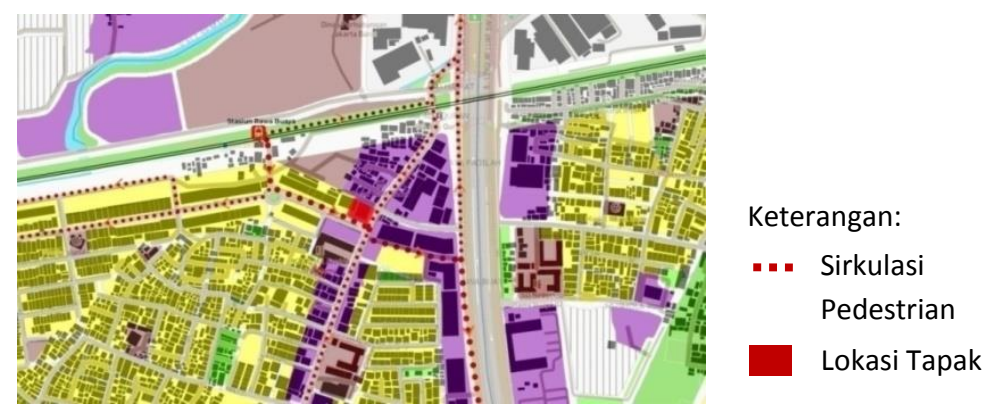

Gambar 3. Mapping Sirkulasi Pedestrian di Sekitar Tapak

Sumber : Penulis, 2020

d. Kesesuaian program wellness terhadap neighborhood

Tapak berbatasan dengan zona hunian dan perkantoran sehingga mendukung program dalam proyek third place yang diperuntukkan bagi siapapun, baik pekerja kantor, pelajar, maupun ibu rumah tangga. 


\section{Massing}

Proses gubahan massa menggunakan bentuk dasar persegi panjang yang kontekstual dengan bentuk massa bangunan sekitar tapak dan diletakkan sejajar dengan tapak. Massa tersebut dikombinasikan dengan massa lain secara diagonal $45^{\circ}$ untuk menanggapi dan menghargai orientasi persimpangan jalan yang menjadikan proyek ini kontras dengan bangunan sekitar yang meletakkan massa sejajar tapak. Massa diagonal ditambah dengan massa tegak lurus yang mengarah ke persimpangan jalan dan membentuk ruang terbuka atau kantung pada sisi kanan, kiri, dan dalam bangunan (void). Ruang terbuka tersebut mendukung program wellness dengan adanya area resapan di area taman dan pengudaraan serta pencahayaan alami di dalam bangunan melalui void yang terbentuk.

Metode responses to site diterapkan dalam membentuk massa yang berorientasi pada lokasi tapak di sudut atau persimpangan jalan dan berhadapan langsung dengan fungsi perkantoran. Hal ini membentuk massa yang rendah di area dekat persimpangan sehingga skyline yang terbentuk semakin tinggi ke arah stasiun dan seluruh massa bangunan dapat dilihat dari arah persimpangan tanpa terhalang massa lain. Selain itu, ketinggian massa yang terbentuk juga merupakan hasil analisis pergerakan dan intensitas pedestrian yang didominasi dari arah arah Stasiun Rawa Buaya. Intensitas pedestrian semakin meningkat ke arah stasiun, sehingga mendukung ketinggian atau skyline massa yang semakin tinggi ke arah stasiun.
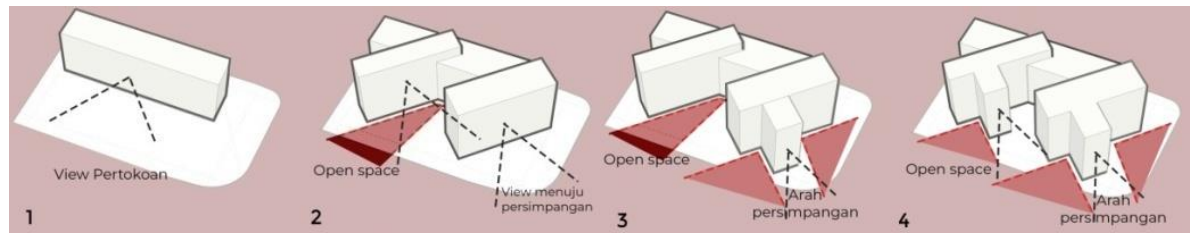

Gambar 4. Diagram Gubahan Massa dengan Ruang Terbuka Sumber : Penulis, 2020

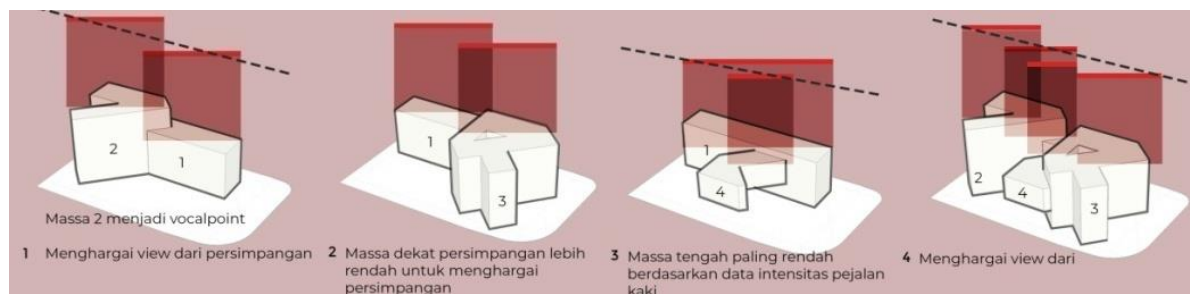

Gambar 5. Diagram Gubahan Massa dengan Orientasi Persimpangan Jalan Sumber : Penulis, 2020

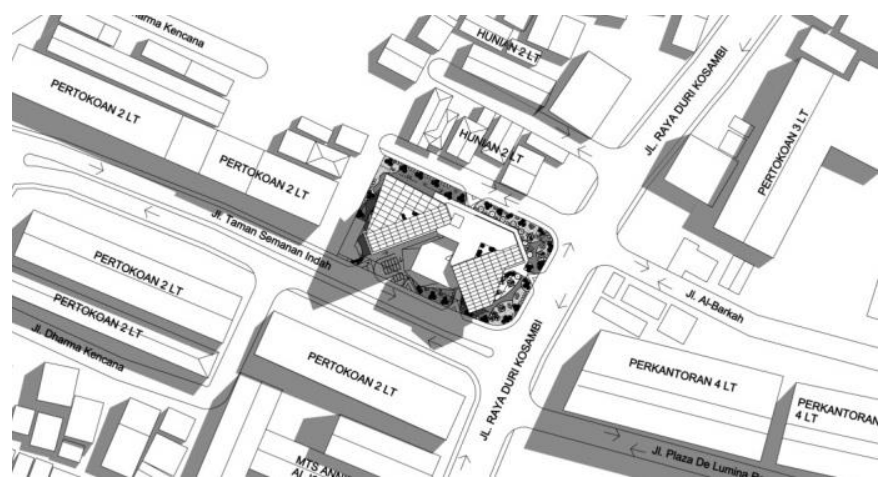

Gambar 6. Blockplan Menunjukkan Bentuk dan Layout Massa yang Kontekstual-Kontras Sumber : Penulis, 2020 


\section{Zoning Program}

Pembagian zoning program di dalam tapak menggunakan pendekatan target di dalam neighborhood. Area depan tapak yang berbatasan dengan zona perkantoran diisi dengan program kapsul tidur indoor dan outdoor, serta outdoor waiting area yang dilengkapi dengan phone charging bench. Area tengah tapak yang menjadi pertemuan zona perkantoran dan hunian diisi dengan program food court, spa dan game station. Area belakang tapak yang berbatasan dengan zona hunian diisi dengan program relaksasi seperti kelas yoga, meditasi, zumba, dan sauna.

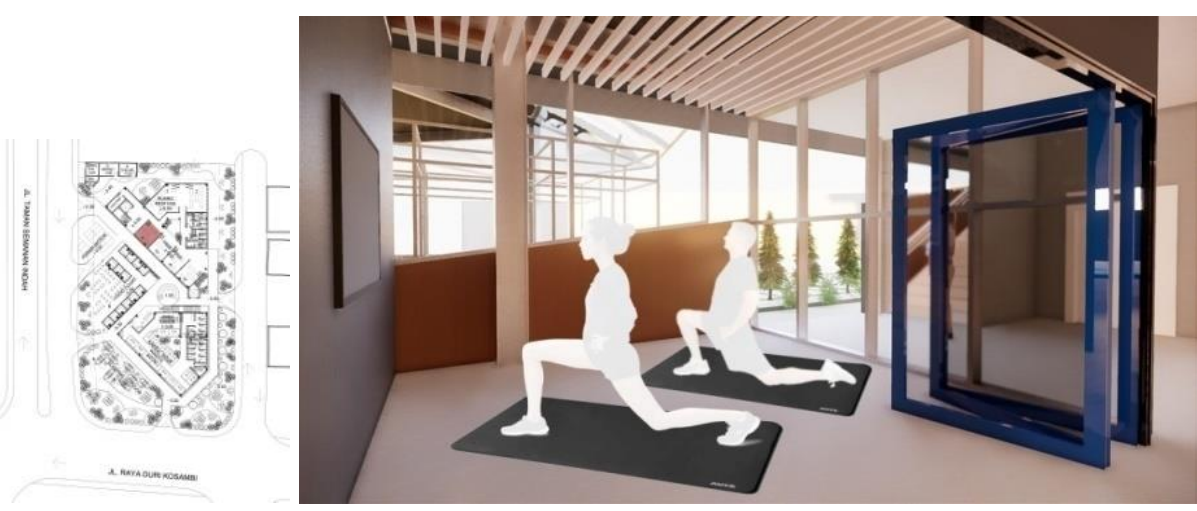

Gambar 7. Kelas Yoga dan Meditasi di Lantai Dasar Sumber: Penulis, 2020

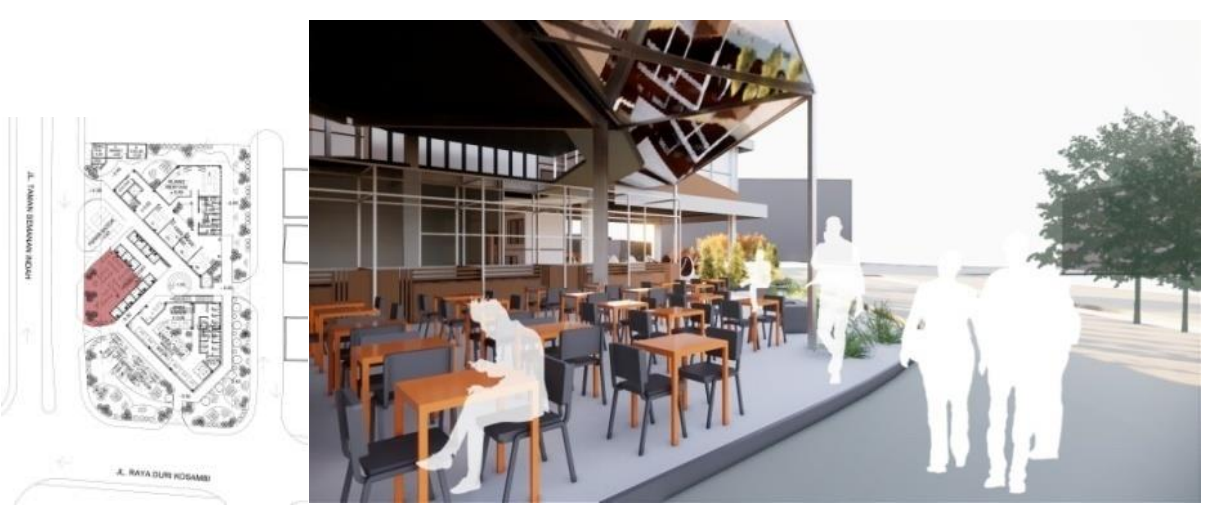

Gambar 8. Food Court di Lantai Dasar Bersifat Semi Terbuka Sumber: Penulis, 2020

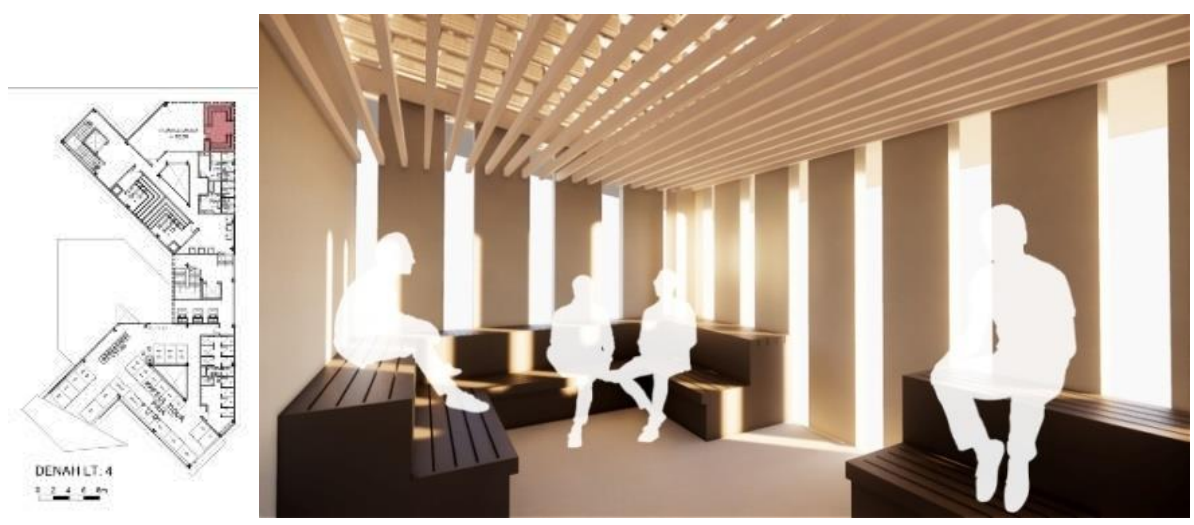

Gambar 9. Suasana Ruang Sauna di Lantai Atas Sumber: Penulis, 2020 


\section{Sistem Struktur}

Bangunan ini menggunakan sistem struktur baja portal dengan dimensi grid 5,7-6m yang disesuaikan dengan kebutuhan ruang dalamnya. Hal ini bertujuan agar cahaya alami dapat masuk ke dalam ruangan dengan mudah dan menyeluruh. Void di tengah bangunan juga memaksimalkan cahaya alami ke dalam ruangan, khususnya pada bagian koridor. Dengan demikian, konsep wellness juga diterapkan di dalam bangunan arsitektur dengan memasukkan pencahayaan alami.

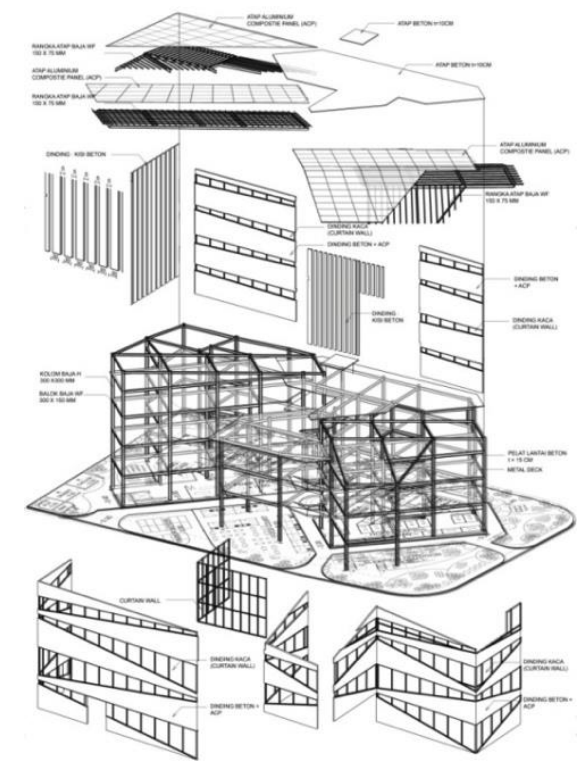

Gambar 10. Axonometric Sistem Struktur Utama dan Finishing Bangunan Sumber : Penulis, 2020

Struktur baja portal pada bangunan terdiri dari kolom dan balok baja yang dikombinasikan dengan beton pada elemen lantai, dinding, serta atap. Kolom menggunakan baja $\mathrm{H}$ berdimensi $300 \times 300 \mathrm{~mm}^{2}$, balok menggunakan baja WF berdimensi $300 \times 150 \mathrm{~mm}^{2}$, dan lantai menggunakan kombinasi metal deck dan beton dengan ketebalan $15 \mathrm{~m}$. Dinding eksterior menggunakan kombinasi antara dinding beton yang dilapisi dengan aluminium composite panel dengan dinding kaca atau curtain wall. Bagian atap bangunan menggunakan atap miring dengan struktur baja dan penutup atap aluminim composite panel. Elemen lantai dan dinding interior menggunakan material beton ekspos. Langit-langit atau plafon menggunakan gypsum pada area koridor dan baffle system pada bagian dalam ruangan seperti kelas yoga, meditasi, zumba dan sauna.

\section{Sistem Mekanikal, Elektrikal \& Plumbing}

Bangunan ini menggunakan dua jenis sistem pengudaraan buatan. Area kapsul tidur indoor menggunakan sistem AC VRV (Variable Refrigerant Volume) dengan komponen outdoor diletakkan di lantai atap bangunan. Area relaksasi seperti spa, kelas yoga, meditasi, zumba yang pemakaian ruangnya tidak bersamaan secara terus menerus menggunakan sistem AC FCU (Fan Coil Unit) dengan komponen cooling tower di lantai atap bangunan, chiller di lantai dasar, serta pipa ducting.

Sistem elektrikal bersumber utama dari Perusahaan Listrik Negara (PLN) dan sumber cadangan genset. Sumber listrik tersebut kemudian dialirkan ke dalam trafo untuk menyetarakan tegangan daya sebelum digunakan ke alat-alat listrik. Panel utama diletakkan di lantai dasar untuk mendistribusikan arus listrik di lantai atas sebelum didistribusikan ke power outlet dan titik lampu. Sistem plumbing bangunan proyek ini menggunakan sumber air air tanah dan Perusahaan Air Minum (PAM) dengan penampungan bawah tanah atau ground water tank sebelum dipompa dan ditampung di reservoir atas. Sumber air ini digunakan untuk kebutuhan 
domestik seperti di kamar mandi, toilet, dan area sink food court serta kebutuhan pemadaman kebakaran dengan sprinkler dan hydrant. Air buangan yang terdiri dari air kotor dan kotoran memiliki sistem buangan yang berbeda. Air kotor langsung dibuang ke riol kota, sedangkan air kotoran diolah terlebih dahulu di dalam sewage treatment plant yang kemudian hasilnya digunakan untuk menyiram tanaman dan flushing toilet. Sistem pemadaman kebakaran terbagi menjadi sprinkler yang diletakkan pada beberapa titik di setiap ruangan, alat pemadam api portable digunakan untuk area memasak di dalam food court, dan hydrant digunakan untuk pemadaman di area taman lantai dasar. Bangunan ini juga dilengkapi dengan lift dan tangga kebakaran.
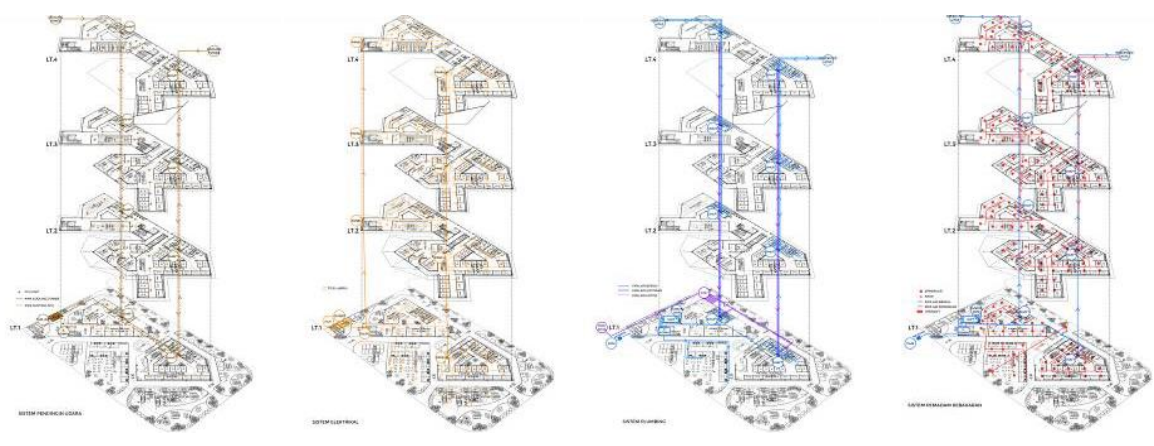

Gambar 11. Axonometric Sistem Mekanikal dan Elektrikal

Sumber: Penulis, 2020

\section{Detail}

Bangunan memiliki ketinggian level yang berbeda pada massa yang berbeda dengan menyesuaikan kebutuhan atau kegiatan program di dalamnya. Massa yang diisi dengan program relaksasi seperti kelas yoga, meditasi, zumba, dan sauna memiliki ketinggian floor to floor $4 \mathrm{~m}$ dan ketinggian floor to ceiling $3.2 \mathrm{~m}$. Sedangkan massa yang diisi dengan program kegiatan tidur memiliki ketinggian floor to floor bervariasi $3.5-4 \mathrm{~m}$ di lantai dasar dan ketinggian floor to ceiling 2.8-3.2m.

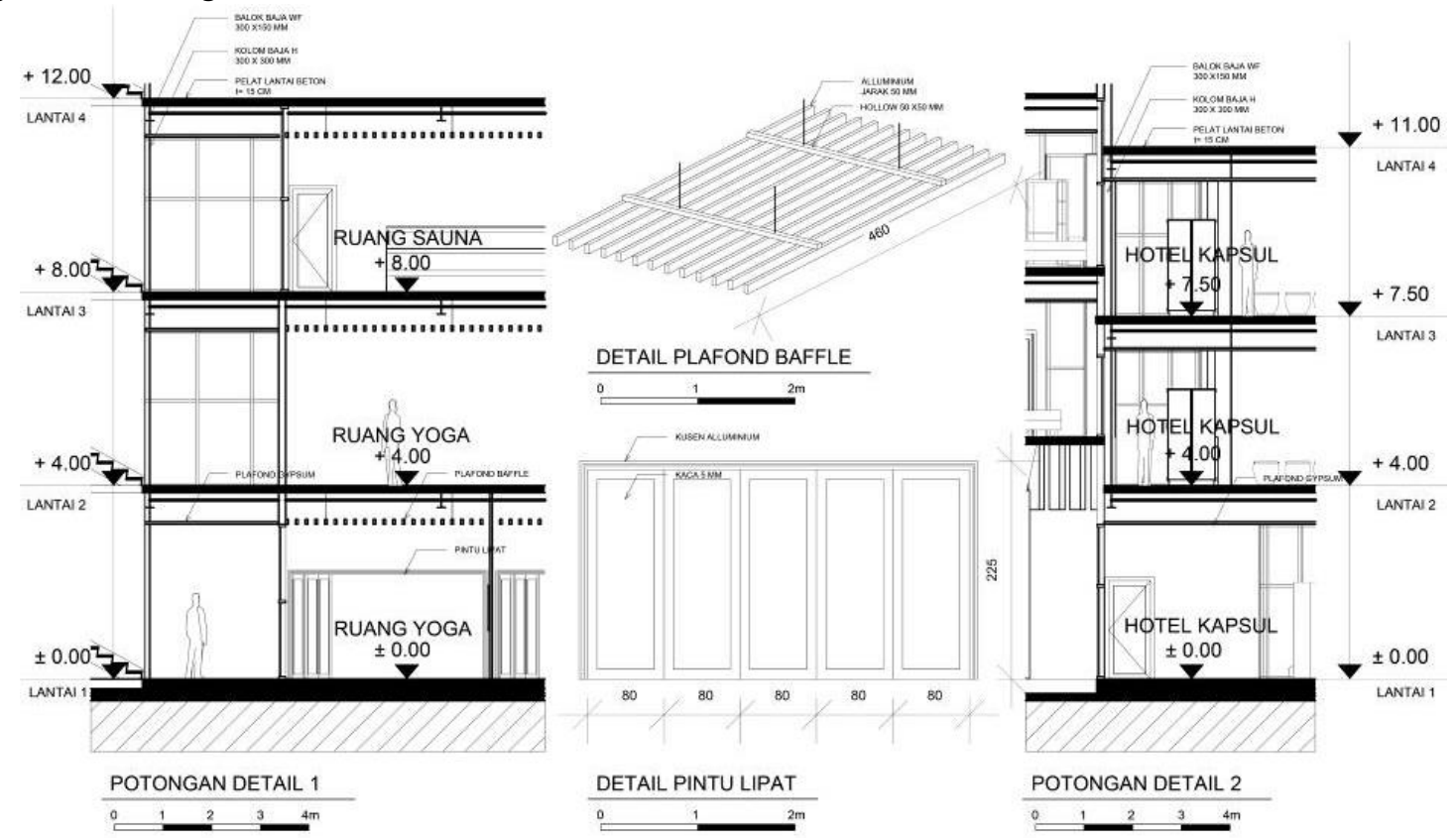

Gambar 12. Detail Ketinggian Level Bangunan

Sumber: Penulis, 2020 
Program kapsul tidur indoor menggunakan kapsul dengan dimensi $2.50 \times 1.50 \times 1.20 \mathrm{~m}^{3}$. Kapsul ini menggunakan material Akrilonitril Butadiena Stiren (ABS), memiliki dua tipe layout memanjang dan memendek dengan pintu geser yang dilengkapi sistem keamanan card reader door lock pada masing-masing kapsul, dan dilengkapi dengan fasilitas interior seperti vent, smart $t v$, dan meja lipat. Food court terdiri dari dua area, diantaranya area tenant dan area makan yang diletakkan di ruang semi terbuka dengan penutup atap UPVC. Area tenant berupa stand atau booth makanan berukuran $2.00 \times 2.00 \mathrm{~m}^{2}$ dengan struktur baja yang mudah dibongkar pasang dan dilengkapi dengan multiplek yang dilapisi High Pressure Laminate (HPL). Area outdoor waiting area yang dilengkapi dengan phone charging bench dapat digunakan untuk mengisi daya perangkat atau smartphone dan juga sebagai tempat duduk. Penggunaan energi listrik berasal dari tenaga surya yang ditangkap melalui panel surya dan disimpan didalam baterai sehingga dapat digunakan untuk mengisi daya.

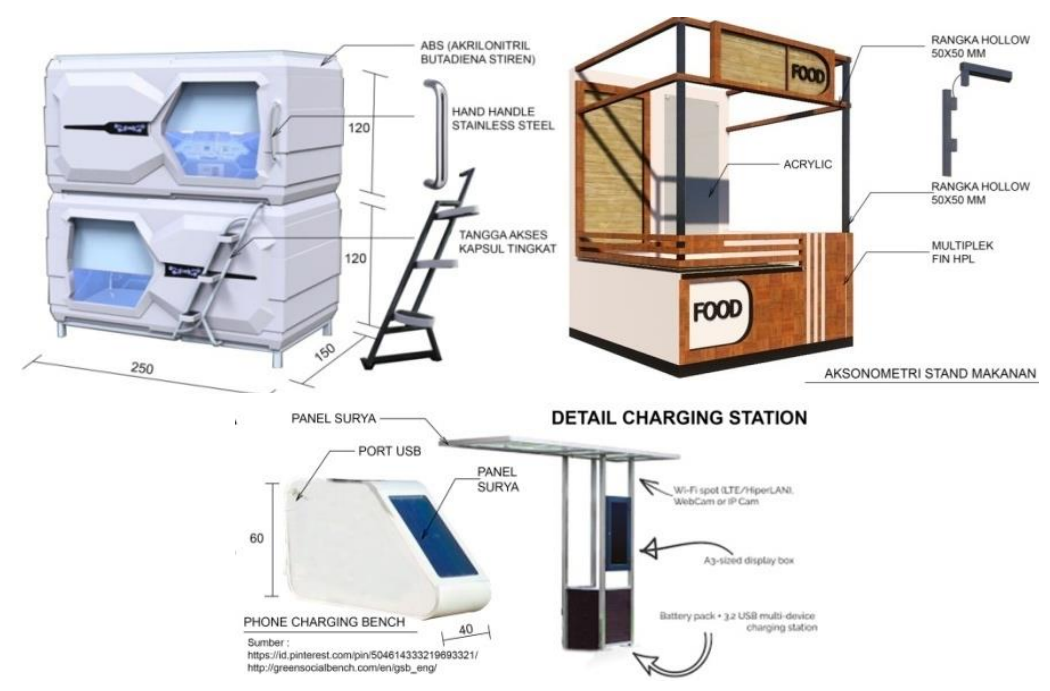

Gambar 13. Detail Axonometric Kapsul Tidur, Food Stand, Phone Charging Bench Sumber: Penulis, 2020

\section{KESIMPULAN}

Aktivitas dan mobilitas masyarakat di sekitar lokasi tapak relatif tinggi karena dipengaruhi dengan keberadaaan stasiun kereta komuter Rawa Buaya yang merupakan gerbang kedatangan komuter di Semanan Indah. Aktivitas perkantoran mendominasi di kawasan ini sehingga membentuk gaya hidup masyarakat kota dengan tingkat kesibukan yang tinggi.

Stasiun Singgah Semanan Indah merupakan proyek third place yang menjadi solusi dari permasalahan di atas yaitu sebagai wadah singgah dan peningkatan gaya hidup sehat (wellness) bagi masyarakat dan komuter di Jakarta. Sebagai suatu third place, proyek ini telah memenuhi beberapa kriteria diantaranya yaitu, netral karena lokasi proyek berada di antara first dan second place; leveler dengan adanya program food court karena menjadi kebutuhan semua orang dari latar belakang yang berbeda; regulars dengan adanya program-program yang dapat diterima oleh masyarakat secara luas seperti food court, kelas yoga, dan kapsul tidur; accessible dengan adanya program yang dapat dapat dijangkau secara finansial oleh seluruh masyarakat seperti outdoor waiting area, phone charging bench, game station, kapsul tidur outdoor, kelas yoga dan meditasi; conversation dengan adanya program yang dapat mendorong terjadinya interaksi antar masyarakat seperi sauna dan game station; dan playful dengan adanya program yang bersifat hiburan dan relaksasi seperti game station dan spa. 
Program-program di dalam proyek Stasiun Singgah Semanan Indah ini menjadi fasilitas bersama sekaligus solusi bagi masyarakat dan komuter Jakarta yang tidak atau belum bisa menerapkan gaya hidup sehat, seperti yoga, meditasi, dan spa. Selain melalui program, lokasi proyek yang berada di pusat aktivitas dan mobilitas juga menjadi solusi di tengah kesibukan masyarakat maupun komuter Jakarta yaitu sebagai tempat singgah sekaligus fasilitas untuk meningkatkan kesehatan (wellness).

Proyek yang berlokasi di perumahan Taman Semanan Indah, Duri Kosambi ini menerapkan metode desain 'responses to site' dengan mempertimbangkan orientasi terhadap sudut atau persimpangan jalan, akses pedestrian, dan bangunan sekitar. Hal ini mempengaruhi bentuk dan peletakkan massa yang menyesuaikan orientasi agar dapat memasukkan cahaya alami, serta zoning atau peletakkan program di dalam bangunan yang menyesuaikan dengan fungsi bangunan sekitar. Ketinggian massa yang berbatasan dengan persimpangan dibuat lebih rendah dari massa di belakangnya dan peletakkan massa utama di area depan dan belakang tapak dengan mempertimbangkan bagian tengah sebagai open space.

\section{REFERENSI}

Asmadi. (2008). Konsep Dasar Keperawatan. Jakarta: Penerbit Buku Kedokteran EGC.

Badan Pusat Statistik. (2016). Penduduk Berumur 10 Tahun Ke Atas yang Rutin Berolahraga. Diakses 22 Mei 2020, dari https://databoks.katadata.co.id/datapublish/2016/11/10/hanya27-penduduk-indonesia-rutin-berolahraga

Badan Pusat Statistik. (2019). Data Kepadatan Penduduk DKI Jakarta. Diakses 20 Juni 2020, dari https://data.jakarta.go.id/dataset/datadkimenurutkepadatanpenduduk

Jormakka, K. (2003). Basics Design Methods. Basel: Birkhäuser Architecture.

Mente, B. L. D. (2010). Exotic Japan The Visual \& Sensual Pleasures. Manila: Phoenix Books.

Millenials At Work Survey Asia Pacific. (2016). Survei: 56 Persen Pekerja Muda Tak Punya Waktu Berolahraga. Diakses 22 Mei 2020, dari https://www.suara.com/health/2016/10/10/170849/survei-56-persen-pekerja-muda-takpunya-waktu-berolahraga

Oldenburg, R. (1999). The Great Good Place: Cafes, Coffee Shops, Bookstores, Bars, Hair Salons, and Other Hangouts at the Heart of a Community. New York: Marlowe \& Company.

Sweeney, T. J. (2000). Adlerian Counseling and Psychotherapy A Practitioner's Approach. New York: Routledge Taylor \& Francis Group. 
